\title{
Optimization and analysis of exergy, economic, and environmental of a combined cycle power plant
}

\author{
M A JAVADI ${ }^{1}, \mathrm{~S} \mathrm{HOSEINZADEH}^{2, *(\mathbb{D}}, \mathrm{M} \mathrm{KHALAJI}^{1}$ and R GHASEMIASL ${ }^{1}$ \\ ${ }^{1}$ Department of Mechanical Engineering, West Tehran Branch, Islamic Azad University, Tehran, Iran \\ ${ }^{2}$ Young Researchers and Elite Club, West Tehran Branch, Islamic Azad University, Tehran, Iran \\ e-mail: Hoseinzadeh.siamak@gmail.com
}

MS received 12 April 2018; revised 30 December 2018; accepted 8 February 2019; published online 23 April 2019

\begin{abstract}
In this study, a combined cycle power plant with a nominal capacity of $500 \mathrm{MW}$, including two gas turbine units and one steam turbine unit, is considered by a mathematical model. This study is carried out to optimize three objective functions of exergy efficiency, $\mathrm{CO}_{2}$ emission and produced power costs. This multiobjective optimization has been carried out by using the Non-Dominated Sorting Genetic Algorithm (NSGA-II). The results indicate that the efficiency of the combined cycle power plant depends on the design parameters including gas turbine input temperature, compressor pressure ratio, and pinch point temperature. Furthermore, any change occurring in these settings may lead to noticeable changes in objective functions, so that the efficiency of this power plant is increased after optimization by up to $8.12 \%$, and its heat rate is correspondingly reduced from $7233(\mathrm{~kJ} / \mathrm{kWh})$ to $7023(\mathrm{~kJ} / \mathrm{kWh})$. Similarly, exergy destruction in the total system shows a reduction by $7.23 \%$.
\end{abstract}

Keywords. Environmental effects; optimization; exergy loss; exergy efficiency; combined cycle.

\section{Introduction}

Given the limitations of energy resources, protecting and moderating the consumption of these resources have become increasingly important. Competition has increased for the development of lower use industries, as well as efforts to find solutions for improving and optimizing energy consumption. In this regard, power plants are considered one of the primary consumers of fuel resources. Exergy analysis, including the determination of exergy at different points along with energy conservation, is a way to evaluate the performance of devices and processes. With this information, the efficiencies can be assessed, and the methods that have the most exergy casualties are identified. Nowadays, many researchers have devoted their studies to analyzing exergy and increasing the efficiency of the individual components of a power generation system.

Sanjay et al investigated Energy and exergy Analysis of the Combined cycle Gas-Steam with Cold Steam, which was a particular type of power plant [1]. In this paper, it is shown that the range of compressor pressure is a fundamental parameter for change to improve efficiency and increase thermal efficiency. The reheat pressure parameter is another critical design parameter for increasing productivity. With the analysis of exergy, it was found that the most

*For correspondence considerable losses in this cycle are related to combustion chamber and turbine.

Sahoo carried out an economics exergy analysis for a cogeneration system which produced $50 \mathrm{MW}$ of electricity and $15 \mathrm{~kg} / \mathrm{s}$ of steam and optimized it using an evolutionary algorithm. The results of his work for an optimal mode in the analysis of economic exergy indicate $9.9 \%$ reduction in the base cost of the system [2]. Barzegar et al have evaluated the ecosystems exergy analysis for a gas turbine plant. The results show that increasing the exergy efficiency reduces the emission of carbon dioxide [3].

Ning-Ning-Sai et al evaluated the exergy for a 1000-MW coal-fired power plant in China. The results show that the heat recovery system is associated with the loss of exergy. Also, $85 \%$ of the exergy loss of the power plant is due to the lack of energy in the combustion chamber and the heat exchangers [4]. Yasser Abdullah and his colleagues conducted an Exergy Assessment for the $180 \mathrm{MW}$ Combined Cycle Power Plant in Sudan. The results of this study also show that the highest exergy destruction occurred in the combustion chamber due to the high irreversibility of the combustion process [5]. There are several methods and approaches in thermo-economics that include: exergy cost theory [6], the theory of explicit exergetic-cost method [7], analysis of thermo-economic functions [8], the applied intelligent approach [9], the principle of last in first out [7], the individual cost approach $[8,10]$, the functional analysis 
of engineering [11, 12] and optimization problems [13-29]. In this study, a particular cost approach is applied.

This research consists of three major parts. In the first part of this study, using the individual cost approach, the cost of exergy is calculated on streamline. In the second part of this research, the optimization of the performance of this system is based on the cost function and exergy efficiency and the amount of power plant emissions. Ultimately, the impact of the parameters affecting the system's performance is studied separately.

Exergy analysis is a particularly attractive subject, which has drawn significant attention both inside and outside of Iran [30-50].

\section{Theory and modeling}

In this research, the combined cycle power plant (CCPP) of Mess (city in Iran) with a nominal capacity of $500 \mathrm{MW}$ has been investigated, as demonstrated in figure 1. The components of this power plant consist of a combination of two gas turbine units and a two-stage steam turbine unit. The gas turbine used on this power plant is V94-2, and its steam turbine is the E-Type of Siemens in which the conditions are illustrated in table 1.

To model this combined cycle power plant, the following assumptions are considered [13].
Table 1. Specifications for the combined cycle power plant of Mess.

\begin{tabular}{lrcr}
\hline $\begin{array}{l}\text { Design } \\
\text { temperature } \\
\left({ }^{\circ} \mathrm{C}\right)\end{array}$ & 15 & $\begin{array}{c}\text { Initial temperature difference } \\
\text { of coolant tower }\left({ }^{\circ} \mathrm{C}\right)\end{array}$ & 45 \\
$\begin{array}{l}\text { Altitude from the } \\
\text { sea level }(\mathrm{m})\end{array}$ & 2000 & Nominal Capacity (MW) & 500 \\
$\begin{array}{l}\text { Condenser } \\
\text { pressure }(\mathrm{kPa})\end{array}$ & 9 & Relative Humidity $(\%)$ & 38 \\
$\begin{array}{l}\text { Heat rate } \\
\left(\mathrm{kW}^{-1} \mathrm{~h}^{-1}\right)\end{array}$ & 7233 & & \\
\hline
\end{tabular}

All processes in this research are stable. The air and exhaust gases from the combustion chamber are considered to be entirely gaseous. The kinetic and potential changes in energy and exergy are neglected. The reference state in this research is $T_{0}=299.15 \mathrm{~K}$ and $P_{0}=1$ bar. The pressure drop in the combustion chamber is considered to be $0.03 \mathrm{kPa}$. Turbine, compressor, and pump are assumed to be adiabatic. The environment temperature and pressure are considered as input conditions into the compressor. The fuel used in this modeling is assumed to be the methane gas.

The econometric exergy analysis refers to the cost associated with the exergy of each flow line. Therefore, to analyze the exergy-economic and the exergy rates of each of the input and output lines to the various components

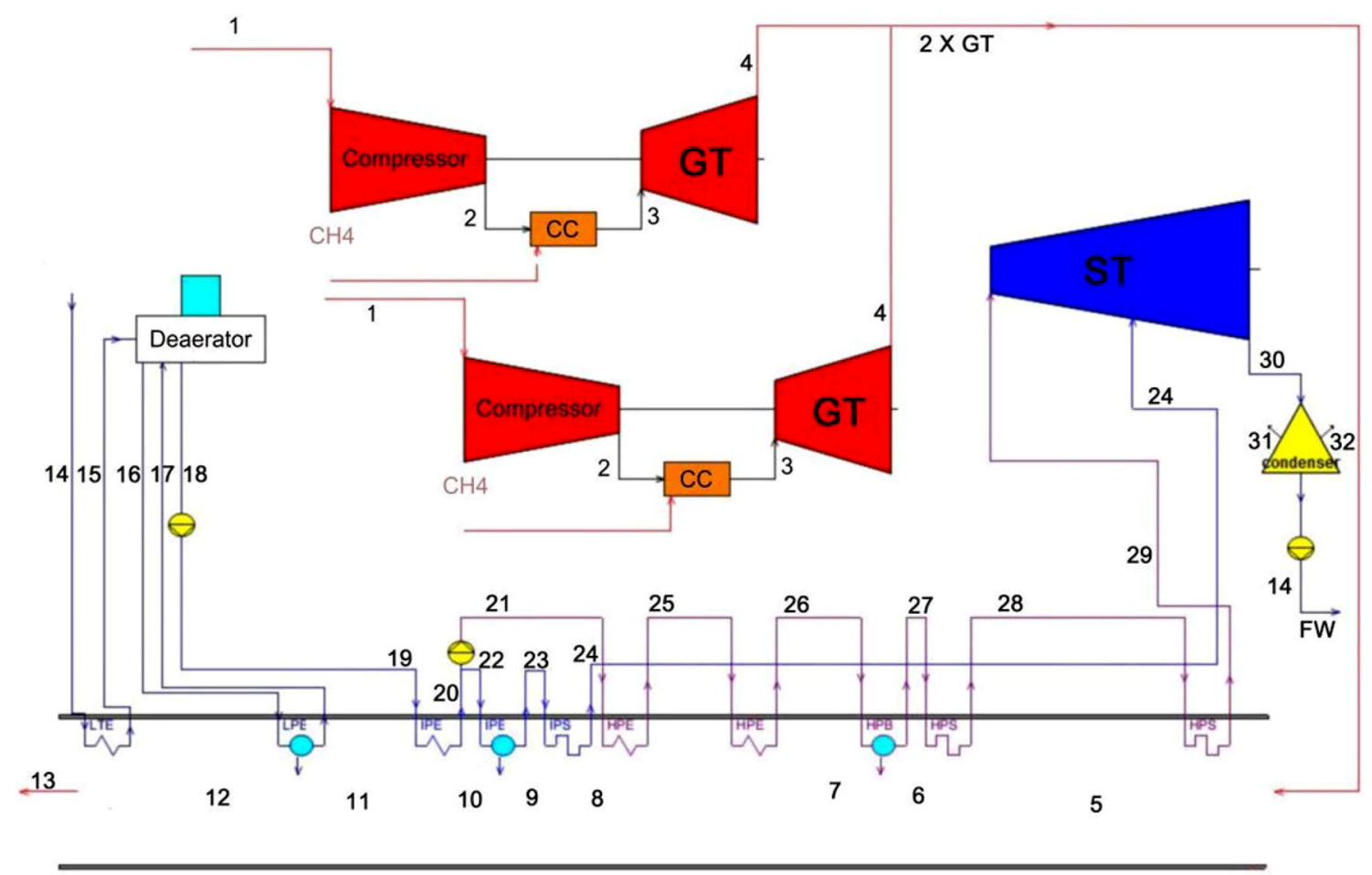

HRSG

Figure 1. Mess combined cycle power plant scheme. 
should be specified. Exergy rates are determined at different points in the power plant by applying the balance of mass, energy, and exergy formulations.

The balance of mass, energy, and exergy for various components of the power plant can be calculated by considering their appropriate control volume applying the following equations $[14,15]$ :

$$
\begin{gathered}
\sum_{I} \dot{m}_{i}=\sum_{e} \dot{m}_{e} \\
\sum_{I} \dot{m}_{i} h_{i}+\dot{Q}=\sum_{e} \dot{m}_{e} h_{e}+\dot{W} \\
\dot{E}_{Q}+\sum_{i} \dot{m}_{i} e_{i}=\sum_{e} \dot{m}_{e} e_{e}+\dot{E}_{W}+\dot{E}_{D}
\end{gathered}
$$

$\dot{E}_{D}$ in (3) represents the rate of exergy destruction. Also, the exergy rate of work $\left(\dot{E}_{\mathrm{W}}\right)$ and the exergy rate of heat transfer at temperature $T$ are calculated from the following relationships, respectively:

$$
\begin{gathered}
\dot{E}_{Q}=\left(1-\frac{T_{0}}{T_{i}}\right) \dot{Q}_{i} \\
\dot{E}_{\mathrm{W}}=\dot{W}
\end{gathered}
$$

The exergy of each of the flow lines at the points shown in figure 1 can be obtained by the following relations $[4,16-19]$ :

$$
\begin{gathered}
\dot{E}=\dot{m} e \\
\dot{E}=\dot{E}_{\mathrm{ph}}+\dot{E}_{\mathrm{ch}} \\
\dot{E}_{p h}=\dot{m}\left[\left(h-h_{0}\right)-T_{0}\left(s-s_{0}\right)\right] \\
\dot{E}_{c h}=\dot{m} e_{\text {mix }}^{\mathrm{ch}} \\
e_{\mathrm{mix}}^{\mathrm{ch}}=\left[\sum_{i=1}^{n} X_{i} e_{\mathrm{i}}^{\mathrm{ch}}+R T_{0} \sum_{k=1}^{n} X_{k} \operatorname{Ln} X_{k}\right]
\end{gathered}
$$

In Eqs. (6) to (10): $\dot{E}$ expresses the exergy flux, $\dot{E}_{\mathrm{ph}}$ the physical exergy flux, $\dot{E}_{\text {ch }}$ the chemical exergy flux, $h$ the specific enthalpy, $T_{0}$ the absolute temperature, $s$ the specific entropy and $X$ is the molar ratio of fuel.

Equation (10) cannot be used to calculate the fuel exergy. Therefore, the fuel exergy is extracted from the following equation that $\xi$ represents the corresponding chemical fuel exergy ratio $[16,20]$ :

$$
\xi=\frac{e_{\mathrm{f}}}{\mathrm{LHV}_{\mathrm{f}}}
$$

The ratio of the chemical exergy of the fuel $e_{\mathrm{f}}$ to the lower heating value $\mathrm{LHV}_{\mathrm{f}}$ is usually close to 1 for gaseous fuels [21].

$$
\xi_{\mathrm{CH}_{4}}=1.06
$$

$$
\xi_{\mathrm{H}_{2}}=0.985
$$

For hydrocarbon fuels $C_{x} H_{y}$, the following empirical relation is used to compute $\xi$ [21]:

$$
\xi=1.033+0.0169 \frac{y}{x}-\frac{0.0698}{x}
$$

In the present research, the exergy of each line and the exergy changes in each component are calculated for the exergy analysis of the power plant.

The thermo-economic calculations of each system are based on the cost of investing its components. Here, we use the cost function proposed by Rosen et al [22]. However, improvements have been made in order to achieve regional conditions in Iran. To convert the cost of investment into cost per unit time, the following relation can be used:

$$
\dot{Z}_{k}=\frac{\mathrm{Z}_{k} C R F \Phi}{(3600 N)}
$$

$Z_{k}$ is the cost of purchasing equipment in dollars. The cost-return factor (CRF) in this equation depends on the estimated interest rate and estimated lifetime for equipment. CRF is calculated according to the following equation:

$$
C R F=\frac{i(1+i)^{n}}{(1+i)^{n}-1}
$$

Here, $i$ is the interest rate, and $n$ is the sum of system operation years [11]. In Eq. (14), $\mathrm{N}$ is the number of hours of operation of the power plant in one year, and $\Phi$ is the maintenance factor, which is equal to 7446 and 1.06, respectively.

In each flow line, to calculate the cost of exergy, the balance equation is written for each component of the power plant separately. There are many thermo-economic approaches in this field. The individual cost method of exergy has been used in this study [10, 18]. This method is based on the specific exergy and the cost of each exergy unit and the auxiliary cost equations for each component of the thermal system. This process consists of three steps: Identification of the exergy stream; the fuel and product for each of the heating system components determination; the formulation of the cost equation for each element of the power plant separately.

The cost associated with the transfer of exergy by the input and output current and the power and heat transfer rate are written as follows $[10,18]$ :

$$
\dot{C}_{\text {in }}=c_{\text {in }} \dot{E}_{\text {in }}=c_{\text {in }}\left(\dot{m}_{\text {in }} e_{\text {in }}\right), \dot{C}_{\text {out }}=c_{\text {out }} \dot{E}_{\text {out }}=c_{\text {out }}\left(\dot{m}_{\text {out }} e_{\text {out }}\right)
$$

$$
\begin{gathered}
\dot{C}_{w}=c_{w} W \\
\dot{C}_{\text {heat }}=c_{\text {heat }} \dot{E}_{\text {heat }}
\end{gathered}
$$


Table 2. Equilibrium cost equations based on special cost approach for gas cycle.

\begin{tabular}{|c|c|c|}
\hline Power plant components & Auxiliary equation & Equilibrium cost equations \\
\hline Compressor 1 & $c_{1}=0$ & $\left(c_{2} \dot{E}_{2}-c_{1} \dot{E}_{1}\right)=c_{\mathrm{w} \cdot \mathrm{BC} 1} \dot{W}_{A C 1}+\dot{Z}_{\mathrm{AC} 1}$ \\
\hline Combustion chamber 1 & - & $c_{3} \dot{E}_{3}=c_{2} \dot{E}_{2}+\dot{Z}_{\mathrm{CC} 1}+\dot{C}_{\mathrm{f}-\mathrm{CC} 1}$ \\
\hline Gas turbine 1 & $c_{3}=c_{4}$ & $c_{\mathrm{w} . \mathrm{BC} 1} \dot{W}_{\mathrm{GT} 1}=\left(c_{3} \dot{E}_{3}-c_{4} \dot{E}_{4}\right)+\dot{Z}_{\mathrm{GT} 1}$ \\
\hline Recovery boiler 1 & $\begin{array}{l}\frac{c_{32} \dot{E}_{32}-c_{30} \dot{E}_{30}}{\dot{E}_{32}-\dot{E}_{30}}=\frac{c_{38} \dot{E}_{38}-c_{36} \dot{E}_{36}}{\dot{E}_{38}-\dot{E}} \\
\frac{c_{38} \dot{E}_{38}-c_{36} \dot{E}_{36}}{\dot{E}_{38}-\dot{E}_{36}}=\frac{c_{44} \dot{E}_{44}-c_{43} \dot{E}_{43}}{\dot{E}_{44}-\dot{E}_{43}} \\
\frac{c_{44} \dot{E}_{44}-c_{43} \dot{E}}{\dot{E}_{44}-\dot{E}}=\frac{c_{46} \dot{E}_{46}-c_{45} \dot{E}_{45}}{\dot{E}_{46}-\dot{E}_{45}} \\
\frac{c_{46} \dot{E}_{46}-c_{45} \dot{E}_{45}}{\dot{E}_{46}-\dot{E}_{45}}=\frac{c_{47} \dot{E}_{47}-c_{46} \dot{E}_{46}}{\dot{E}_{47}-\dot{E}_{46}} \\
\frac{c_{47} \dot{E}_{47}-c_{46} \dot{E}_{46}}{\dot{E}_{47}-\dot{E}_{46}}=\frac{c_{52} \dot{E}_{52}-c_{51} \dot{E}_{51}}{\dot{E}_{52}-\dot{E}_{51}} \\
\frac{c_{52} \dot{E}_{52}-c_{51} \dot{E}_{51}}{\dot{E}_{52}-\dot{E}_{51}}=\frac{c_{53} \dot{E}_{53}-c_{52} \dot{E}_{52}}{\dot{E}_{53}-\dot{E}_{52}} \\
\frac{c_{53} \dot{E}_{53}-c_{52} \dot{E}_{52}}{\dot{E}_{53}-\dot{E}_{52}}=\frac{c_{54} \dot{E}_{54}-c_{53} \dot{E}_{53}}{\dot{E}_{54}-\dot{E}_{53}}\end{array}$ & $\begin{array}{l}\left(c_{32} \dot{E}_{32}-c_{30} \dot{E}_{30}\right)+\left(c_{38} \dot{E}_{38}-c_{36} \dot{E}_{36}\right) \\
+\left(c_{44} \dot{E}_{44}-c_{43} \dot{E}_{43}\right)+\left(c_{46} \dot{E}_{46}-c_{45} \dot{E}_{45}\right) \\
+\left(c_{47} \dot{E}_{47}-c_{46} \dot{E}_{46}\right)+\left(c_{52} \dot{E}_{52}-c_{51} \dot{E}_{51}\right) \\
+\left(c_{53} \dot{E}_{53}-c_{52} \dot{E}_{52}\right)+\left(c_{54} \dot{E}_{54}-c_{53} \dot{E}_{53}\right) \\
=\left(c_{4} \dot{E}_{4}-c_{13} \dot{E}_{13}\right)+\dot{C}_{\mathrm{f}-\mathrm{db} 1}+\dot{Z}_{\mathrm{HRSG} 1}\end{array}$ \\
\hline Compressor 2 & $\begin{array}{c}c_{13}=c_{4} \\
c_{14}=0\end{array}$ & $\left(c_{15} \dot{E}_{15}-c_{14} \dot{E}_{14}\right)=c_{\mathrm{w} \cdot \mathrm{BC} 2} \dot{W}_{\mathrm{AC} 2}+\dot{Z}_{\mathrm{AC} 2}$ \\
\hline Combustion chamber 2 & - & $c_{16} \dot{E}_{16}=c_{15} \dot{E}_{15}+\dot{Z}_{\mathrm{CC} 2}+\dot{C}_{\mathrm{f}-\mathrm{CC} 2}$ \\
\hline Gas turbine 2 & $c_{16}=c_{17}$ & $c_{\mathrm{w} . \mathrm{BC} 2} \dot{W}_{\mathrm{GT} 2}=\left(c_{16} \dot{E}_{16}-c_{17} \dot{E}_{17}\right)+\dot{Z}_{\mathrm{GT} 2}$ \\
\hline \multirow[t]{2}{*}{ Booster Recovery 2} & $\begin{array}{l}\frac{c_{33} \dot{E}_{33}-c_{31} \dot{E}_{31}}{\dot{E}_{33}-\dot{E}_{31}}=\frac{\left(c_{39} \dot{E}_{39}-c_{37} \dot{E}_{37}\right)}{\dot{E}_{39}-\dot{E}_{37}} \\
\frac{\left(c_{39} \dot{E}_{39}-c_{37} \dot{E}_{37}\right)}{\dot{E}_{39}-\dot{E}_{37}}=\frac{c_{56} \dot{E}_{56}-c_{55} \dot{E}_{55}}{\dot{E}_{56}-\dot{E}_{55}} \\
\frac{c_{56} \dot{E}_{56}-c_{55} \dot{E}_{55}}{\dot{E}_{56}-\dot{E}_{55}}=\frac{c_{58} \dot{E}_{58}-c_{57} \dot{E}_{57}}{\dot{E}_{58}-\dot{E}_{57}} \\
\frac{c_{58} \dot{E}_{58}-c_{57} \dot{E}_{57}}{\dot{E}_{58}-\dot{E}_{57}}=\frac{c_{59} \dot{E}_{59}-c_{58} \dot{E}_{58}}{\dot{E}_{59}-\dot{E}_{58}} \\
\frac{c_{59} \dot{E}_{59}-c_{58} \dot{E}_{58}}{\dot{E}_{59}-\dot{E}_{58}}=\frac{c_{61} \dot{E}_{61}-c_{60} \dot{E}_{60}}{\dot{E}_{61}-\dot{E}_{60}} \\
\frac{c_{61} \dot{E}_{61}-c_{60} \dot{E}_{60}}{\dot{E}_{61}-\dot{E}_{60}}=\frac{c_{62} \dot{E}_{62}-c_{61} \dot{E}_{61}}{\dot{E}_{62}-\dot{E}_{61}} \\
\frac{c_{62} \dot{E}_{62}-c_{61} \dot{E}_{61}}{\dot{E}_{62}-\dot{E}_{61}}=\frac{c_{63} \dot{E}_{63}-c_{62} \dot{E}_{62}}{\dot{E}_{63}-\dot{E}_{62}}\end{array}$ & $\begin{array}{l}\left(c_{33} \dot{E}_{33}-c_{31} \dot{E}_{31}\right)+\left(c_{39} \dot{E}_{39}-c_{37} \dot{E}_{37}\right) \\
+\left(c_{56} \dot{E}_{56}-c_{55} \dot{E}_{55}\right)+\left(c_{58} \dot{E}_{58}-c_{57} \dot{E}_{57}\right) \\
+\left(c_{59} \dot{E}_{59}-c_{58} \dot{E}_{58}\right)+\left(c_{61} \dot{E}_{61}-c_{60} \dot{E}_{60}\right) \\
+\left(c_{62} \dot{E}_{62}-c_{61} \dot{E}_{61}\right)+\left(c_{63} \dot{E}_{63}-c_{62} \dot{E}_{62}\right) \\
=\left(c_{17} \dot{E}_{17}-c_{26} \dot{E}_{26}\right)+\dot{C}_{\mathrm{f}-\mathrm{db} 2}+\dot{Z}_{\mathrm{HRSG} 2}\end{array}$ \\
\hline & $c_{17}=c_{26}$ & \\
\hline
\end{tabular}

In which $c_{\text {in }}, c_{\text {out }}, c_{w}$ and $c_{\text {heat }}$ represent the average cost of the exergy unit. Accordingly, the cost equilibrium equation for the power plant component is written based on the following equation:

$$
\sum\left(c_{\text {in }} \dot{E}_{\text {in }}\right)_{k}+C_{w, k} W_{k}=\sum\left(c_{\text {out }} \dot{E}_{\text {out }}\right)_{k}+c_{\text {heat }, k} \dot{E}_{\text {heat }, k}+\dot{Z}_{k}
$$

In the above equation, the positive and negative sign for $W_{k}$ will be used for input and output power, respectively [10]. Using cost equilibrium equations and auxiliary equations for each component, a set of linear equations that their concurrent response will result in the cost of each flow line. Therefore, the value and auxiliary balance equations are based on the unique cost approach for the various components of the combined cycle power plant under the conditions given in tables 2 and 3 .

In this section of the analysis, two concepts of fuel and product are defined. In the equation of equilibrium cost (20), no cost term directly correlates with the destruction of the exergy of the components. Accordingly, the cost associated with the removal of exergy in an element or process will be a hidden cost, which only appears in the thermo-economic analysis [18, 23, 24].

$$
\begin{aligned}
& \dot{C}_{P, k}=\dot{C}_{F, k}-\dot{C}_{L, k}+\dot{Z}_{k} \quad \text { and } \\
& \quad c_{P, k} \dot{E}_{P, k}=c_{F, k} \dot{E}_{F, k}-\dot{C}_{L, k}+\dot{Z}_{k}
\end{aligned}
$$

In Eq. (21): $\dot{\mathrm{C}}_{\mathrm{P}, \mathrm{k}}$ expresses the Cost rates associated with Product for the kth component, $\dot{\mathrm{C}}_{\mathrm{F}, \mathrm{k}}$ The Cost rates associated with Fuel for the kth component, $\dot{\mathrm{C}}_{\mathrm{L}, \mathrm{k}}$ the Cost rates associated with Exergy Loss for the kth component, $\dot{Z}_{k}$ the Capital Cost rates for the kth component, $c_{\mathrm{P}, \mathrm{k}}$ the average unit cost of the Product for the kth component and $c_{\mathrm{F}, \mathrm{k}}$ is the average unit cost of the fuel for the kth component.

$$
\dot{E}_{P, k}=\dot{E}_{F, k}-\dot{E}_{L, k}+\dot{E}_{D, k}
$$

$\dot{\mathrm{E}}_{\mathrm{L}, \mathrm{k}}$ expresses the rate of Exergy Loss for the kth component, $\dot{\mathrm{E}}_{\mathrm{D}, \mathrm{k}}$ the rate of Exergy Destruction for the kth component, $\dot{\mathrm{E}}_{\mathrm{F}, \mathrm{k}}$ the Exergy rate of the fuel for the kth 
Table 3. Equilibrium equations based on cost approach for steam cycle.

\begin{tabular}{lcc}
\hline Power plant components & Auxiliary equation & Equilibrium cost equations \\
\hline Steam turbine & $c_{65}=c_{64}=c_{27}$ & $c_{\mathrm{w} \cdot \mathrm{RC}} \dot{W}_{\mathrm{ST}}=\left(c_{65} \dot{E}_{65}+c_{64} \dot{E}_{64}-c_{27} \dot{E}_{27}\right)+\dot{Z}_{\mathrm{ST}}$ \\
Condenser & - & $c_{28} \dot{E}_{28}=c_{27} \dot{E}_{27}+\dot{Z}_{\mathrm{Cond}}$ \\
Pump & - & $\left(c_{29} \dot{E}_{29}-c_{28} \dot{E}_{28}\right)=c_{\mathrm{w} \cdot \mathrm{RC}} \dot{W}_{\mathrm{p}}+\dot{Z}_{\mathrm{p}}$ \\
DeEriter & - & $c_{34} \dot{E}_{34}+c_{40} \dot{E}_{40}+\dot{Z}_{\text {Dea }, \mathrm{BFP}-\mathrm{LP}}=c_{35} \dot{E}_{35}+c_{42} \dot{E}_{42}$ \\
\hline
\end{tabular}

component and $\dot{\mathrm{E}}_{\mathrm{P}, \mathrm{k}}$ is the Exergy rate of the product for the kth component. By elimination $\dot{\mathrm{E}}_{\mathrm{F}, \text { kand }}$ and $\dot{E}_{P, k}$, Eqs. (21) and (23) are obtained:

$$
\begin{aligned}
& c_{P, k} \dot{E}_{P, k}=c_{F, k} \dot{E}_{P, k}+\left(c_{F, k} \dot{E}_{L, k}-\dot{C}_{L, k}\right)+\dot{Z}_{k}+c_{F, k} \dot{E}_{D, k} \\
& c_{P, k} \dot{E}_{F, k}=c_{F, k} \dot{E}_{F, k}+\left(c_{P, k} \dot{E}_{L, k}-\dot{C}_{L, k}\right)+\dot{Z}_{k}+c_{P, k} \dot{E}_{D, k}
\end{aligned}
$$

The last term on the right of Eqs. (24) and (25) will include the rate of exergy destruction. As discussed above, assuming that the product exergy is assumed to be constant and the cost of the unit of fuel $c_{F, k}$ for the $\mathrm{k}$ component is independent of the exergy destruction, the cost of the exergy degradation is defined by the last term of equation (25) [18].

$$
\dot{C}_{D, k}=c_{F, k} \dot{E}_{D, k}
$$

The amount of carbon monoxide and nitrous oxide emissions in the combustion chamber are due to the combustion reaction, which is related to various properties, including the adiabatic flame temperature. The adiabatic flame temperature can be calculated from the following equation $[3,17]$.

$$
T_{p z}=A \sigma^{\alpha} \exp \left(\beta(\sigma+\lambda)^{2}\right) \pi^{x^{*}} \theta^{y^{*}} \xi^{z^{*}}
$$

In this equation, $\pi$ and $\theta$ represent the dimensionless pressure and temperature values and $\xi$ is the $\mathrm{H} / \mathrm{C}$ atomic ratio. Also, for $\varphi \leq 1$, the value of $\sigma$ is equal to $\varphi$ and for $\varphi>1$ its value is calculated from the relation $\sigma=\varphi-0.7$, where $\varphi$ is molar or mass ratio. Also $\mathrm{x}, \mathrm{y}$, and $\mathrm{z}$ are second order functions of $\sigma$ :

$$
\begin{aligned}
& x^{*}=a_{1}+b_{1} \sigma+c_{1} \sigma^{2} \\
& y^{*}=a_{2}+b_{2} \sigma+c_{2} \sigma^{2} \\
& z^{*}=a_{3}+b_{3} \sigma+c_{3} \sigma^{2}
\end{aligned}
$$

The values of the above parameters are in table 4 . The amount of carbon monoxide and oxides of nitrogen produced in the combustion chamber depends on the variation of
Table 4. Constants of Eqs. (27) to (30) [17].

\begin{tabular}{lcclcc}
\hline & \multicolumn{2}{c}{$1.0 \leq \varphi \leq 1.6$} & & \multicolumn{2}{c}{$0.3 \leq \varphi \leq 1.0$} \\
\cline { 2 - 3 } \cline { 5 - 6 } Constants & $2 \leq \theta \leq 3.2$ & $0.92 \leq \theta \leq 2$ & & $2 \leq \theta \leq 3.2$ & $0.92 \leq \theta \leq 2$ \\
\hline$A$ & 1246.177 & 916.826 & & 2361.764 & 2361.764 \\
$\alpha$ & 0.381 & 0.288 & & 0.115 & 0.115 \\
$\beta$ & 0.347 & 0.145 & & -0.948 & -0.948 \\
$\lambda$ & -2.036 & -3.277 & & -1.097 & -1.097 \\
$a 1$ & 0.036 & 0.031 & & 0.014 & 0.014 \\
$b 1$ & -0.085 & -0.078 & & -0.055 & -0.055 \\
$c 1$ & 0.051 & 0.049 & & 0.052 & 0.052 \\
$a 2$ & 0.009 & 0.025 & & 0.395 & 0.395 \\
$b 2$ & 0.502 & 0.260 & & -0.441 & -0.441 \\
$c 2$ & -0.247 & -0.131 & & 0.141 & 0.141 \\
$a 3$ & 0.017 & 0.004 & & 0.005 & 0.005 \\
$b 3$ & -0.189 & -0.178 & & -0.128 & -0.128 \\
$c 3$ & 0.103 & 0.098 & & 0.082 & 0.082 \\
\hline
\end{tabular}

combustion properties in the flame's adiabatic temperature relationship. The following relationship gives the values of the two gases in grams per kilogram of fuel.

$$
\begin{gathered}
\dot{m}_{\mathrm{NO}_{\mathrm{x}}}=\frac{0.15 \times 10^{16} \tau^{0.5} \exp \left(-71100 / T_{\mathrm{pz}}\right)}{p_{3}^{0.05} \tau\left(\Delta p_{\mathrm{in}} / p_{\mathrm{in}}\right)^{0.5}} \\
\dot{m}_{\mathrm{co}}=\frac{0.179 \times 10^{9} \exp \left(7800 / T_{\mathrm{pz}}\right)}{p_{3}^{2} \tau\left(\Delta p_{\mathrm{in} / p_{\text {in }}}\right)^{0.5}}
\end{gathered}
$$

Also, $\tau$ is the remainder in the combustion zone (assuming the value of $\tau$ is constant and equal to $0.022 \mathrm{sec}-$ onds). $\Delta p_{\text {in }} / p_{\text {in }}$ is the amount of pressure drop in the combustion chamber. These equations are based on the experimental values obtained to estimate the amount of carbon monoxide and nitrous oxide emissions [17].

As the amount of material emission in the combustion chamber of the turbine is of the PPM order, the combustion process is assumed to be complete in the combustion chamber.

If the combustion process is assumed to be complete in a combustion chamber, the carbon dioxide emission can be calculated from the following equation [17]: 


$$
\dot{m}_{\mathrm{CO}_{2}}=44.01 \times x \times\left(\dot{m}_{\text {fuel } / m_{\text {fuel }}}\right)
$$

That $\mathrm{x}$ is the molar ratio of carbon in the fuel and $m_{\text {fuel }}$ is the molar mass of fuel. This simple equation estimates the amount of carbon dioxide emissions in a complete combustion process accurately.

Multi-objective optimization is used to optimize the CCPP. Therefore, to achieve this goal, two different target functions are defined. The first objective function of the CCPP exergy efficiency is obtained by dividing the network output of the entire power plant into the fuel exergy according to the following equation [20].

$$
\eta_{e x}=\frac{\sum \dot{W}_{\text {net }}}{\dot{E}_{\mathrm{f}}}
$$

The second objective function consists of a set of costs for the components of the plant, the fuel cost used in the combustion chamber and the fire channel, and the cost associated with the exergy degradation.

$$
\begin{gathered}
\dot{C}_{\text {Total }}=\dot{C}_{\mathrm{F}}+\sum_{k} \dot{Z}_{k}+\dot{C}_{\mathrm{Env}}+\dot{C}_{D} \\
\dot{C}_{E n v}=c_{\mathrm{co}} \dot{m}_{\mathrm{CO}}+c_{\mathrm{NO}_{\mathrm{x}}} \dot{m}_{\mathrm{NO}_{\mathrm{x}}}+c_{\mathrm{CO}_{2}} \dot{m}_{\mathrm{CO}_{2}} \\
\dot{C}_{F}=c_{\mathrm{f}} \dot{m}_{\mathrm{f}} \times \mathrm{LHV}
\end{gathered}
$$

The third objective is the amount of carbon dioxide emissions by the combined cycle power plant calculated from the following equation.

$$
\epsilon=\frac{\dot{m}_{\mathrm{CO}_{2}}}{\dot{W}_{\text {net }}}
$$

In this multi-purpose optimization, maximizing the exergy efficiency and minimizing the overall cost rate along with the amount of pollution is considered. It is evident that with increasing exergy efficiency, the total cost will increase.

To optimize, there are a number of control variables: compressor compression ratio $r_{\mathrm{AC}}$, isentropic compressor efficiency $\eta_{\mathrm{AC}}$, gas turbine isentropic efficiency $\eta_{\mathrm{AC}}$, gas turbine input temperature (TIT), high pressure pinch point $P P_{\mathrm{HP}}$, the temperature of the low pressure pinch point $P P_{\mathrm{LP}}$, the input temperature to the high pressure steam turbine $T_{\mathrm{HP}}$, the inlet temperature to the low pressure steam turbine $T_{\mathrm{LP}}$, the condenser pressure $P_{\mathrm{Cond}}$, the isentropic pump efficiency $\eta_{\text {Pump }}$ and isentropic steam turbine efficiency $\eta_{\mathrm{ST}}$. These design parameters will be used for optimizing.

Also, due to limitations such as selecting a suitable alloy for the gas turbine or commercial acceptability, etc. as constraints in this research (table 5).
Table 5. The range of decision variables.

Reasons for the applied constraints Optimization constraints

Temperature limit for the alloy

Economic acceptability $T I T<1550 \mathrm{~K}$ $r_{\mathrm{AC}}<12$

Economic acceptability

Economic acceptability

Economic acceptability

Economic acceptability

Limit of thermal efficiency

Avoid formation of sulfuric acid

Heat transfer limitation

$\eta_{\mathrm{AC}}<0.9$

$\eta_{\mathrm{GT}}<0.9$

$0.75<\eta_{\mathrm{ST}}<0.9$

$0.75<\eta_{\text {Pump }}<0.9$

5 bar $<P_{\text {Cond }}<15$ bar

$T_{\text {HRSG.Out }} \geq 120^{\circ} \mathrm{C}$

$5^{\circ} \mathrm{C}<P P_{\mathrm{HP}}, P P_{\mathrm{LP}}<45^{\circ} \mathrm{C}$
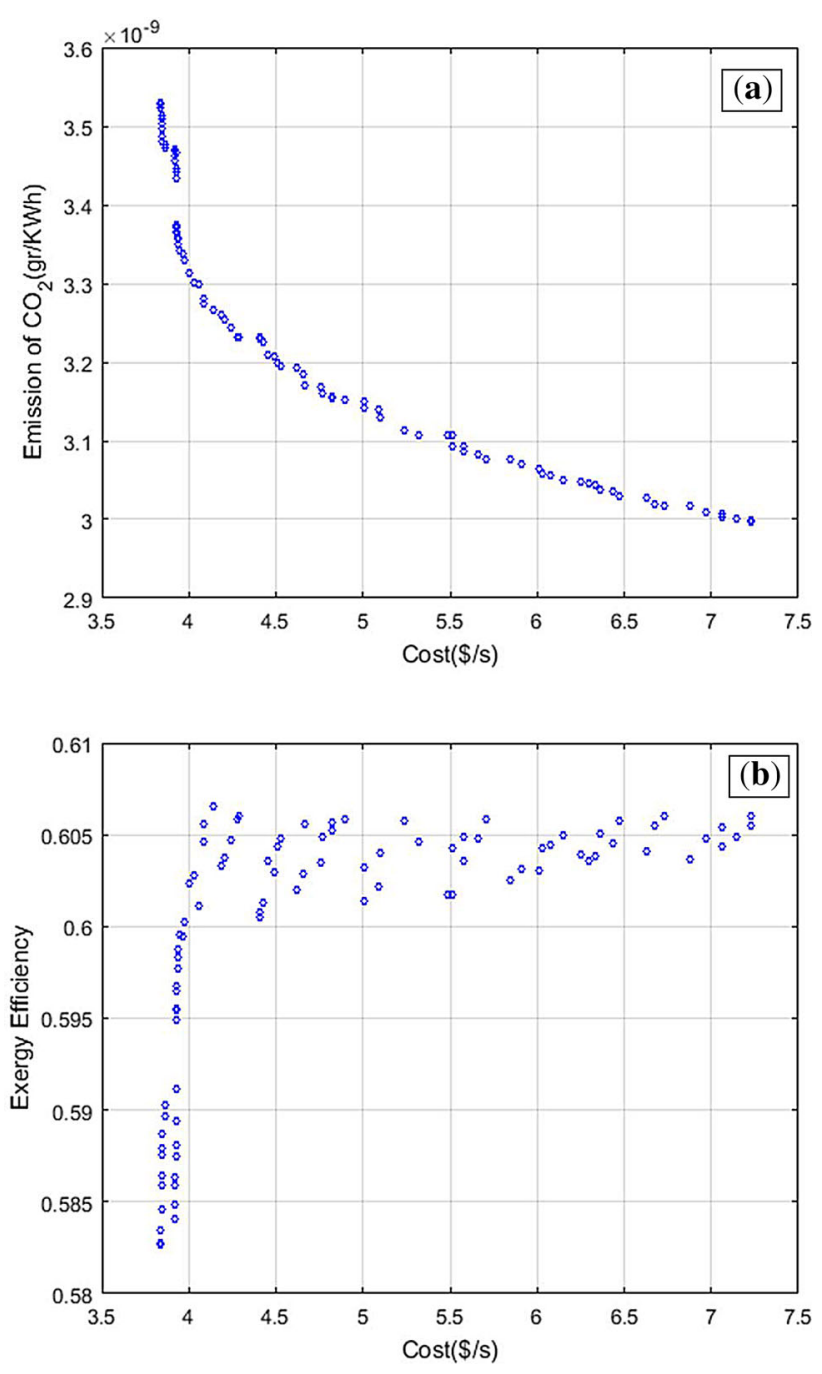

Figure 2. (a, b) Pareto Front. 
Table 6. Comparison of decision variables before and after optimization.

\begin{tabular}{|c|c|c|c|c|c|c|c|c|c|c|c|}
\hline Design variables & $\begin{array}{l}\eta_{S T} \\
(\%)\end{array}$ & $\begin{array}{c}\eta_{\text {Pump }} \\
(\%)\end{array}$ & $\begin{array}{l}P_{\text {Cond }} \\
(\mathrm{Kpa})\end{array}$ & $\begin{array}{l}T_{L P} \\
(\mathrm{~K})\end{array}$ & $\begin{array}{l}T_{H P} \\
(\mathrm{~K})\end{array}$ & $\begin{array}{c}P P_{H P} \\
(\mathrm{~K})\end{array}$ & $\begin{array}{c}P P_{H P} \\
(\mathrm{~K})\end{array}$ & $\begin{array}{c}G T I T \\
(\mathrm{~K})\end{array}$ & $\begin{array}{l}\eta_{G T} \\
(\%)\end{array}$ & $\begin{array}{l}\eta_{A C} \\
(\%)\end{array}$ & $r_{A C}$ \\
\hline Before optimization & 70 & 90 & 9.3 & 488.15 & 783.15 & 30 & 25 & 1323.15 & 80 & 87 & 10 \\
\hline After optimization & 89 & 75 & 20 & 578.21 & 829.89 & 52 & 45 & 1473.5 & 87 & 91 & 10.69 \\
\hline
\end{tabular}

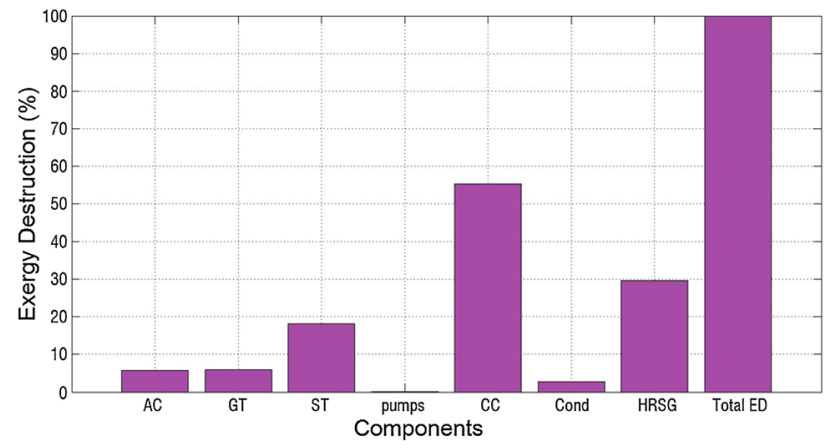

Figure 3. Exergy destruction of each component of the power plant in percent.

\section{Result}

Using the relationships described in the previous section for each component of the combined cycle power plant and applying the constraints listed in table 5, multi-objective optimization has been done on the design variables. Figure 2 shows the optimization results from the three objective function of exergy efficiency and the total cost of producing electricity and carbon dioxide emissions for a combined cycle power plant in the Pareto front. In figures 2(a) and 2(b) increasing the exergy efficiency from $48 \%$ to $51 \%$, the cost of the produced electricity will increase significantly. In fact, the highest exergy efficiency at the end point of the Pareto front line is to the right of the

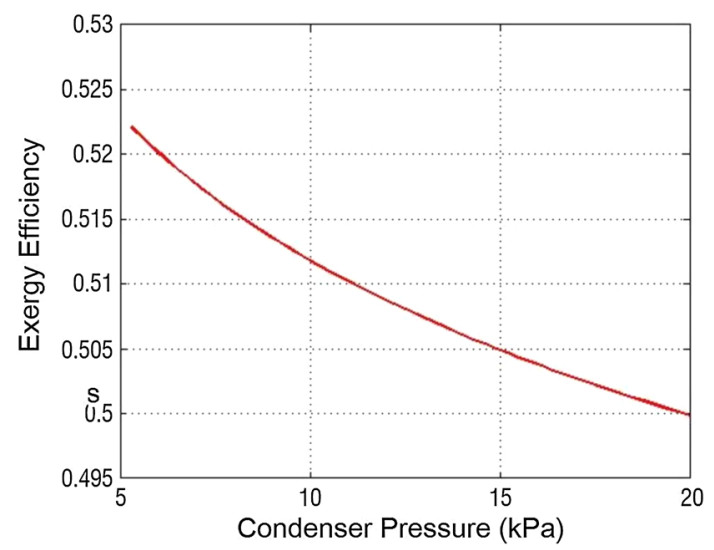

Figure 4. The effect of condenser pressure changes on exergy efficiency.

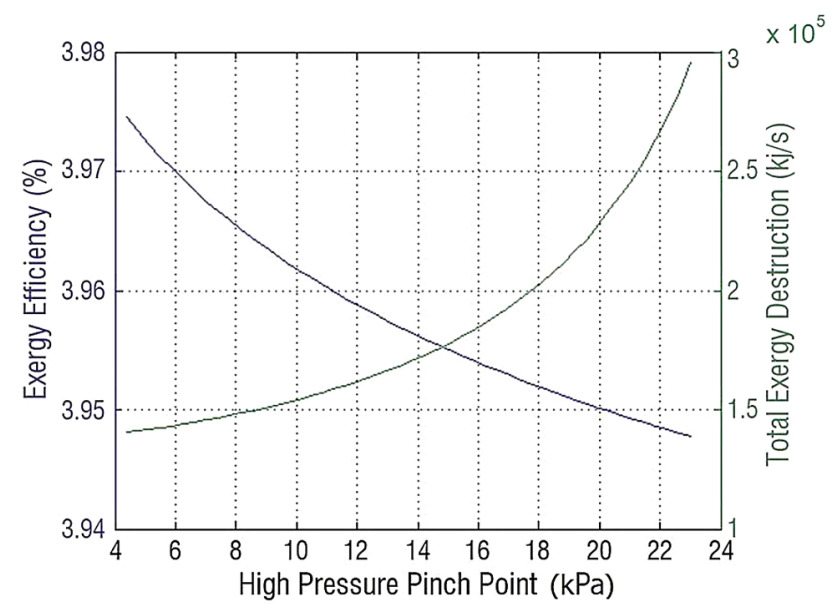

Figure 5. Exergy degradation rate of the power plant Effect of change in pinch point on the exergy efficiency and the amount of exergy destruction of the entire power plant.

graph, $(51 \%)$, at which point we will have the highest total cost of the electricity $(6.768 \$ / \mathrm{s})$.

To optimize the multi-objective, a solution to the decision-making process is needed from the solution to the final solution. The decision-making process is accomplished with the help of the equilibrium point, which is an ideal state. The simultaneous access of three target functions to optimal values is impossible, and the balance point does not fit on the Pareto front, and at the point of maximum exergy efficiency and the minimum for cost and carbon dioxide emissions. The nearest point to the equilibrium point on the Pareto front can be considered as the final answer. However, the Pareto optimal front has a weak balance, which means that with a small change in the efficiency of exergy, the electricity generation rate will change a lot. In fact, in Multi-Purpose Optimization and Pareto's solution, you can use any point as an optimization point. Therefore, selecting the optimal response can vary depending on the criteria and criteria of the decision maker. Given the objective functions and the constraints applied to them, as well as the use of the genetic algorithm for this problem, one can obtain decision variables for a combined cycle power plant with the optimal final point. The optimum point in figure 2 is marked with a red color that has the nearest distance to the equilibrium point.

In the present Study, a comparison of decision variables before and after optimization has been shown in table 6 . 


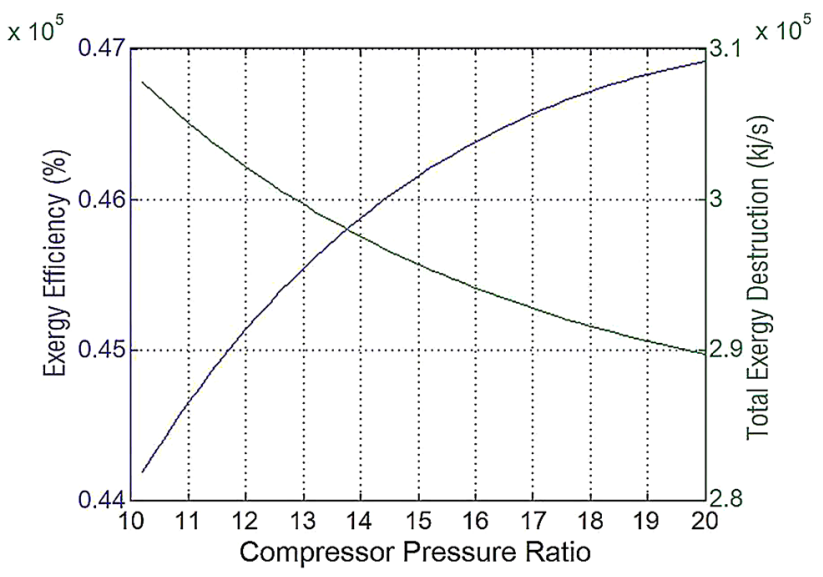

Figure 6. Effect of the compressor compression coefficient change on exergy efficiency.

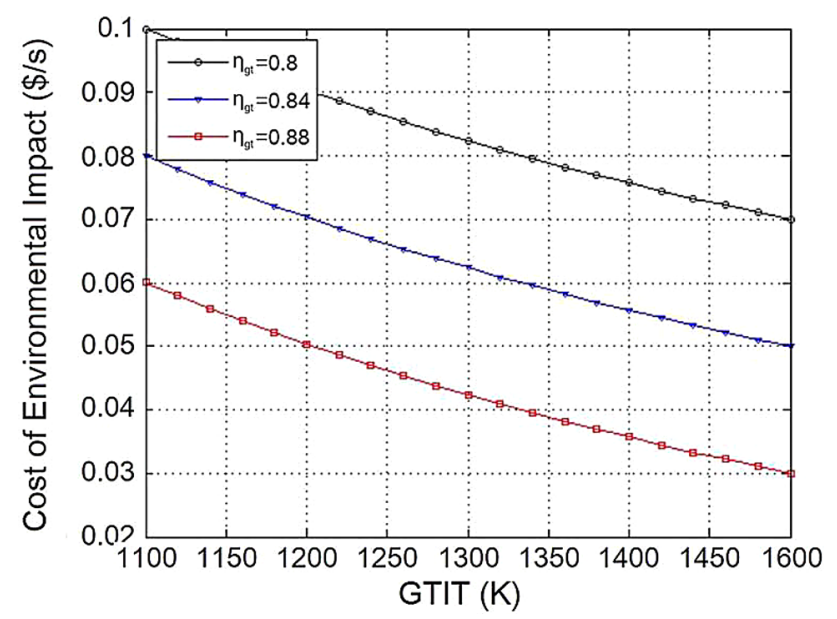

Figure 7. Power plant: the effect of changing the temperature of the input to the gas turbine on the amount of power plant effluent effects.

Sensitivity analysis is performed on some target functions, to understand the effect of decision variables on them better; figure 3 shows the magnitude of exergy degradation in each of the plant's components. In this chart, the most significant exergy destruction occurs in the combustion chamber and the lowest in the pumps.

Condenser pressure is another important design parameter in power plants. Figure 4 shows that with increasing this design parameter, the exergy efficiency decreases due to increased heat dissipation from the power plant to the environment. In fact, by changing the pressure of the condenser in the range of 5 to $20 \mathrm{kPa}$, the total exergy efficiency of the entire power plant will be reduced by about $2 \%$.

Figure 5 shows that by changing the temperature of the high-pressure pinch point, both the parameters of the exergy efficiency and the destruction rate of exergy change. Also, It is observed that by increasing the temperature of

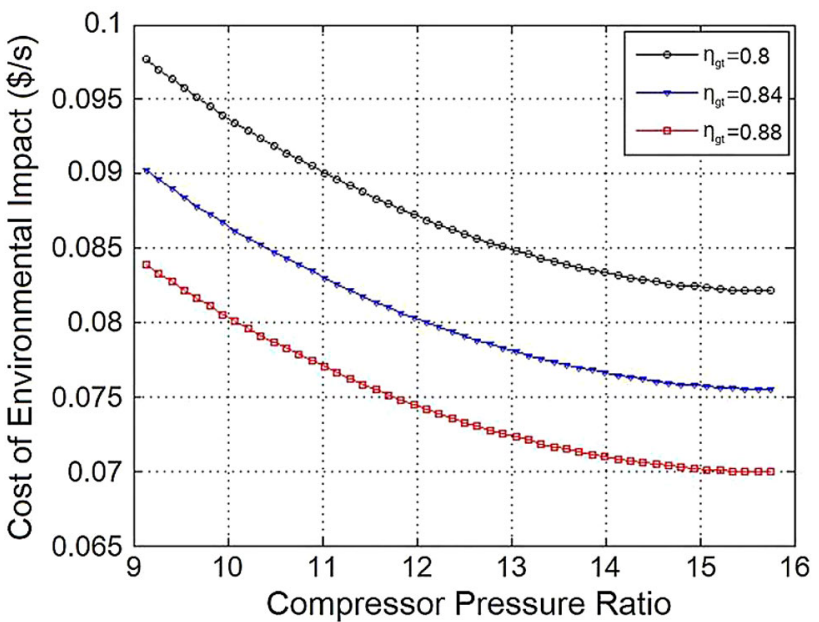

Figure 8. Effect of compressor compression coefficient change on cost of pollutant effects.

the pinch point, the effectiveness of the exergy decreases, which means lower energy supply for the steam line and will reduce the output power of the steam turbine. Meanwhile, the increase of the exergy rate of destruction indicates an increase in irreversibility in the recovery boiler, and the increase in the rate of exergy destruction increases with this change.

Figure 6 shows the changes in exergy efficiency and total exergy degradation relative to changes in the temperature of the gas entering the gas turbine. Also, It is perceived that with increasing compressor compression ratio due to lower fuel consumption, the efficiency of exergy increases and thus the amount of exergy destruction decreases to $6.45 \%$.

By increasing the compressor ratio, the exergy efficiency can grow, but given the need for more air to compress it, the overall cost of the electricity produced will increase.

Figure 8 shows that by increasing the compressor pressure, the cost of the power plant's emissions decreases. This is because the fuel injection rate inside the combustion chamber decreases and the pollutant emissions increase by decreasing the gas turbine efficiency.

Also, with the increase in the input temperature to the gas turbine, the amount of pollutant emissions in the combined cycle power plant will be reduced by about $0.003 \$$ per second, which is significant as shown in figure 7. Finally, with the reduction of the gas turbine efficiency, the amount of pollution also increases.

\section{Conclusion}

By applying the decision-making variables resulting from this optimization, the efficiency of the power plant is increased by $8.12 \%$ and the exergy efficiency is increased by $10 \%$. Also, the influence of decision variables such as compressor compression ratio, gas turbine input 
temperature; pinch point temperature on two proposed target functions has been investigated. Accordingly, with increasing compressor compression ratio, the exergy efficiency of the combined cycle increases. Of course, with growing exergy efficiency, the total exergy loss of the entire cycle will be reduced. Increasing the compressor compression ratio alone would improve the effectiveness of the power plant by $1.09 \%$ and also increase the exergy efficiency by $1.11 \%$. The input temperature to the gas turbine enhances the ability of the power plant by $2.53 \%$ and the exergy efficiency of $2.39 \%$.

Furthermore, according to the contents expressed it can be concluded that the analysis exergy economic cost approach is an extraordinarily useful tool for identifying and evaluating inefficiencies concerning cost and efficiency. Plus the methods and equations used in this study were limited to heating systems. Also, it is usable in another order. Moreover, based on the results expressed, it can be concluded that the analysis exergyeconomic cost approach is a beneficial tool for identifying and evaluating inefficiencies and cost efficiency. The methods and equations used in this study were limited to heating systems and this can also be used in other systems.

\section{Nomenclature}

$c \quad$ cost per exergy unit (\$/MJ)

$c_{\mathrm{f}} \quad$ cost of fuel per energy unit (\$/MJ)

$\dot{C} \quad$ cost flow rate $(\$ / \mathrm{s})$

$c_{p} \quad$ specific heat at constant pressure $(\mathrm{kJ} / \mathrm{kg} \mathrm{K})$

$C R F$ capital recovery factor

$E \quad$ exergy $\left(\frac{\mathrm{MJ}}{\mathrm{kg}}\right)$

$f \quad$ exergoeconomic factor

$\dot{E} \quad$ exergy flow rate (MW)

$\dot{E}_{D} \quad$ exergy destruction rate (MW)

$\dot{\mathrm{E}}_{\mathrm{W}} \quad$ exergy rate of work (MW)

$e \quad$ specific exergy $(\mathrm{kJ} / \mathrm{kg})$

$\mathrm{e}_{\mathrm{f}} \quad$ chemical exergy of the fuel $(\mathrm{kJ} / \mathrm{kg})$

$i \quad$ annual interest rate (\%)

$\mathrm{h} \quad$ specific enthalpy $(\mathrm{kJ} / \mathrm{kg})$

$\mathrm{h}_{0} \quad$ specific enthalpy at environmental state $(\mathrm{kJ} / \mathrm{kg})$

LHV lower heating value $(\mathrm{kJ} / \mathrm{kg})$

$\dot{m} \quad$ mass flow rate $(\mathrm{kg} / \mathrm{s})$

$\mathrm{n}$ number of years

$\mathrm{N}$ number of hours of plant operation per year

PP pinch point

$\dot{Q} \quad$ heat transfer rate $(\mathrm{kW})$

$r_{A C} \quad$ compressor pressure ratio

$s \quad$ specific entropy $(\mathrm{kJ} / \mathrm{kg} \mathrm{K})$

$s_{0} \quad$ specific entropy at environmental state $(\mathrm{kJ} / \mathrm{kg} \mathrm{K})$

$T_{0} \quad$ absolute temperature (K)

$\dot{W}_{\text {net }} \quad$ net power output (MW)

Z capital cost of a component (\$)

$\dot{Z} \quad$ capital cost rate $(\$ / \mathrm{s})$

\section{Greek letters}

$\eta \quad$ isentropic efficiency

$\xi$ coefficient of fuel chemical exergy

$\sigma$ standard deviation

$\Phi$ maintenance factor

$\pi$ dimensionless pressure values

$\theta$ dimensionless temperature values

\begin{tabular}{ll}
\multicolumn{2}{l}{ Subscripts } \\
$a$ & air \\
AC & air compressor \\
CC & combustion chamber \\
ch & chemical \\
Cond & condenser \\
D & exergy destruction \\
f & fuel \\
GT & gas turbine \\
HP & high pressure \\
HRSG & heat recovery steam generator \\
$i$ & ith trial vector \\
$k$ & kth component \\
LP & low pressure \\
ph & physical \\
tot & total \\
ST & steam turbine \\
sys & system \\
w & water
\end{tabular}

\section{References}

[1] Tsatsaronis G, Lin L and Pisa J 1993 Exergy costing in exergoeconomics. Journal of Energy Resource-ASME 115: $9-16$

[2] Sahoo P K 2008 Exergoeconomic analysis and optimization of a cogeneration system using evolutionary programming. Applied Thermal Engineering 28(13): 1580-8

[3] BarzegarAvval H, Ahmadi P, Ghaffarizadeh A and Saidi M H 2011 Thermoeconomic-environmental multiobjective optimization of a gas turbine power plant with preheater using evolutionary algorithm. International Journal of Energy Research 35: 389-403

[4] Si N, Zhao Z, Su S, Han P, Sun Z, Xu J, Cui X, Hu S, Wang Y, Jiang L, Zhou Y, Chen G and Xiang J 2017 Exergy analysis of a $1000 \mathrm{MW}$ double reheat ultra-supercritical power plant. Energy Conversion and Management 147: 155-165

[5] Abuelnuor A A A, Saqr K M, Mohieldein S A A, Dafallah K A, Abdullah M M, Abdullah Y and Nogoud M 2017 Exergy analysis of Garri "2" 180 MW combined cycle power plant. Renewable and Sustainable Energy Reviews 79: 960-969

[6] Lozano M A and Valero A 1993 Theory of the exergetic cost. Energy 18:939-60

[7] Erlach B, Serra L and Valero A 1999 Structural theory as standard for thermoeconomics. Energy Conversion and Management 40: 1627-1649

[8] Frangopoulos C A 1987 Thermo-economic functional analysis and optimization. Energy 12: 563-571 
[9] Frangopoulos C A 1991 Intelligent functional approach: a method for analysis and optimal synthesis-design-operation of complex systems. Journal of Energy Environment Economics 1: 267-74

[10] Lazzaretto A and Tsatsaronis G 2006 SPECO: "a systematic and general methodology for calculating efficiencies and costs in thermal systems". Energy 31:1257-89

[11] Von Spakovsky M R 1994 Application of engineering functional analysis to the analysis and optimization of the CGAM problem. Energy 19: 343-64

[12] Von Spakovsky M R and Evans R B 1993 Engineering functional analysis - Parts I and II. Journal of Energy Resource-ASME 115: 86-99

[13] Pratap S, Daultani Y, Tiwari M K and Mahanty B 2018 Rule based optimization for a bulk handling port operations. Journal of Intelligent Manufacturing 29(2): 287-311

[14] Chan F T S, Jha A and Tiwari M K 2016 Bi-objective optimization of three echelon supply chain involving truck selection and loading using NSGA-II with heuristics algorithm. Applied Soft Computing Journal 38: 978-987

[15] Chaube A, Benyoucef L and Tiwari M K 2012. An adapted NSGA-2 algorithm based dynamic process plan generation for a reconfigurable manufacturing system. Journal of Intelligent Manufacturing 23(4): 1141-1155

[16] Dixit V, Seshadrinath N and Tiwari M K 2016. Performance measures based optimization of supply chain network resilience: A NSGA-II + Co-Kriging approach. Computers and Industrial Engineering 93: 205-214

[17] Tiwari A, Chang P C and Tiwari M K 2012 A highly optimised tolerance-based approach for multi-stage, multi-product supply chain network design. International Journal of Production Research 50(19): 5430-5444

[18] Mogale D G, Kumar M, Kumar S K and Tiwari M K 2018 Grain silo location-allocation problem with dwell time for optimization of food grain supply chain network. Transportation Research Part E: Logistics and Transportation Review 111: 40-69

[19] Dolgui A, Tiwari M K, Sinjana Y, Kumar S K and Son Y J 2018 Optimising integrated inventory policy for perishable items in a multi-stage supply chain. International Journal of Production Research 56(1-2): 902-925

[20] Patne K, Shukla N, Kiridena S and Tiwari M K 2018 Solving closed-loop supply chain problems using game theoretic particle swarm optimisation. International Journal of Production Research 56(17): 5836-5853

[21] Maiyar L M, Cho S J, Tiwari M K, Thoben K D and Kiritsis D 2018 Optimising online review inspired product attribute classification using the self-learning particle swarm-based Bayesian learning approach. International Journal of Production Research. Taylor and Francis Ltd. https://doi.org/10. 1080/00207543.2018.1535724

[22] Maiyar L M and Thakkar J J 2017. A combined tactical and operational deterministic food grain transportation model: Particle swarm based optimization approach. Computers and Industrial Engineering 110: 30-42

[23] Maiyar L M, Thakkar J J, Awasthi A and Tiwari M K 2015. Development of an effective cost minimization model for food grain shipments. In: IFAC-PapersOnLine 28: 881-886

[24] Jawad H, Jaber M Y and Nuwayhid R Y 2018 Improving supply chain sustainability using exergy analysis. European Journal of Operational Research 269(1): 258-271
[25] Bilgen S and Sarikaya I 2015 Exergy for environment, ecology and sustainable development. Renewable and Sustainable Energy Reviews.

[26] Mogale D G, Kumar,S K and Tiwari M K 2018 An MINLP model to support the movement and storage decisions of the Indian food grain supply chain. Control Engineering Practice 70: 98-113

[27] Mogale D G, Kumar M, Kumar S K and Tiwari M K 2018 Grain silo location-allocation problem with dwell time for optimization of food grain supply chain network. Transportation Research Part E: Logistics and Transportation Review 111: 40-69

[28] Di Somma M, Yan B, Bianco N, Graditi G, Luh P B, Mongibello L and Naso V 2017. Design optimization of a distributed energy system through cost and exergy assessments. Energy Procedia 105: 2451-2459

[29] Bahlouli K 2018 Multi-objective optimization of a combined cycle using exergetic and exergoeconomic approaches. Energy Conversion and Management 171: 1761-1772

[30] Hoseinzadeh S, Ghasemiasl R, Havaei D and Chamkha A J 2018 Numerical investigation of rectangular thermal energy storage units with multiple phase change materials. Journal of Molecular Liquids 271: 655-660

[31] Hoseinzadeh S, Moafi A, Shirkhani A and Chamkha A J 2019 Numerical validation heat transfer of rectangular crosssection porous fins. Journal of Thermophysics and Heat Transfer 1-7. https://doi.org/10.2514/1.T5583

[32] Hoseinzadeh S, Sahebi S A R, Ghasemiasl R and Majidian A R 2017 Experimental analysis to improving thermosyphon (TPCT) thermal efficiency using nanoparticles/based fluids (water). European Physical Journal Plus 132(5). https://doi. org/10.1140/epjp/i2017-11455-3

[33] Yari A, Hosseinzadeh S, Golneshan A A and Ghasemiasl R 2015 Numerical simulation for thermal design of a gas water heater with turbulent combined convection ( $\mathrm{p}$. V001T03A007). ASME International. https://doi.org/10. 1115/ajkfluids2015-3305

[34] Yousef Nezhad M E and Hoseinzadeh S 2017 Mathematical modelling and simulation of a solar water heater for an aviculture unit using MATLAB/SIMULINK. Journal of Renewable and Sustainable Energy 9(6). https://doi.org/10. 1063/1.5010828

[35] Hoseinzadeh S, Hadi Zakeri M, Shirkhani A and Chamkha A J 2019 Analysis of energy consumption improvements of a zero-energy building in a humid mountainous area. Journal of Renewable and Sustainable Energy 11(1). https://doi.org/ 10.1063/1.5046512

[36] Hoseinzadeh S and Azadi R 2017 Simulation and optimization of a solar-assisted heating and cooling system for a house in Northern of Iran. Journal of Renewable and Sustainable Energy 9(4). https://doi.org/10.1063/1.5000288

[37] Javadi M A and Ghomashi H 2016 Thermodynamics analysis and optimization of Abadan combined cycle power plant. Indian Journal of Science and Technology 9

[38] Habibi H, Yari A, Hosseinzadeh S and Burkhani S D 2016 Numerical study of fluid flow around a diver helper. International Journal of Recent advances in Mechanical Engineering (IJMECH) 5(1). https://doi.org/10.14810/ijmech. 2016.5105

[39] Hosseinzadeh S, Galogahi M R and Bahrami A 2014 Performance prediction of a turboshaft engine by using of one 
dimensional analysis. International Journal of Recent Advances in Mechanical Engineering 3: 99-108

[40] Yari A, Hosseinzadeh S and Galogahi M R, 2014 Two-dimensional numerical simulation of the combined heat transfer in channel flow. International Journal of Recent Advances in Mechanical Engineering 3: 55-67

[41] Hosseinzadeh S, Yari A, Abbasi E and Absalan F 2014 The numerical study of channel flow in turbulent free convection with radiation and blowing. International Journal of Recent Advances in Mechanical Engineering 3: 11-26

[42] Hosseinzadeh S, Yari A, Abbasi E and Absalan F 2014 The numerical study of channel flow in turbulent free convection with radiation and blowing. International Journal of Recent Advances in Mechanical Engineering 3: 11-26

[43] Kohzadi H, Shadaram A and Hoseinzadeh S 2018 Improvement of the centrifugal pump performance by restricting the cavitation phenomenon. Chemical Engineering Transactions 71: 1369-1374

[44] Hosseinzadeh S, Ostadhossein R, Mirshahvalad H R and Seraj J 2017 Using simpler algorithm for cavity flow problem. An International Journal (MECHATROJ) 1

[45] Ghasemi A, Dardel M, Ghasemi M H and Barzegari M M 2013 Analytical analysis of buckling and post-buckling of fluid conveying multi-walled carbon nanotubes. Appl. Math. Model. 37: 4972-4992

[46] Ghasemi A, Dardel M and Ghasemi M H 2012 Control of the non-linear static deflection experienced by a fluid-carrying double-walled carbon nanotube using an external distributed load. Proceedings of the Institution of Mechanical Engineers, Part N: Journal of Nanoengineering and Nanosystems 226: 181-190

[47] Ghasemi A, Dardel M and Ghasemi M H 2015 Collective effect of fluid's coriolis force and nanoscale's parameter on instability pattern and vibration characteristic of fluid-conveying carbon nanotubes. Journal of Pressure Vessel Technology 137: 031301-10

[48] Bahrami A, Hosseinzadeh S, Ghasemiasl R and Radmanesh M 2015 Solution of non-Fourier temperature field in a hollow sphere under harmonic boundary condition. Applied Mechanics and Materials 772: 197-203

[49] Eftari M, Hoseinzadeh S, Javaniyan H and Emadi M F T 2012 Analytical solution for free convection non-Newtonian flow between two vertical sheets. World Applied Sciences Journal 16 (Special Issue of Applied Math): 01-06

[50] Hoseinzadeh S 2012 Experimental investigation on thermal performance using nanofluid. August Archives Des Sciences Journal 65(8): 22-29 